\title{
POSSIBILIDADES E DESAFIOS DA INICIAÇÃO À DOCÊNCIA EM TEATRO NA EDUCAÇÃO BÁSICA ${ }^{1}$ Vera Lúcia Bertoni dos Santos ${ }^{2}$
}

\section{Resumo}

O texto traz um apanhado do trabalho de iniciação docente realizado no Subprojeto de Teatro da UFRGS do Programa Institucional de Bolsas de Iniciação à Docência (PIBID), que compreende uma proposta de qualificação da formação profissional do professor de teatro através da interação entre estudantes Bolsistas do Curso de Licenciatura em Teatro da UFRGS e a realidade de uma escola da Rede Pública Estadual de Ensino do Rio Grande do Sul. As ações do Subprojeto de Teatro desenvolvem-se na cidade de Porto Alegre, no Instituto de Educação General Flores da Cunha (IE), e têm por objetivo central restabelecer as funções do núcleo teatral da escola - o TIPIE. Nesse sentido, consideram-se as possibilidades e os desafios às ações de iniciação à docência em teatro, dentre as quais se destacam: o conhecimento acerca da estrutura e do funcionamento da escola; a inserção dos futuros professores no ambiente escolar; a pesquisa acerca da memória da escola, com ênfase no seu papel precursor para o ensino de teatro em âmbito local e nacional; o desenvolvimento de oficinas de iniciação teatral oferecidas à comunidade do IE; e a retomada das funções artísticas e culturais do TIPIE.

PALAVRAS-CHAVE: Ensino de teatro; formação de professores; escola; pesquisa.

\section{Abstract}

This paper gives a critical overview on the Institutional Undergraduate Scholarship Program on Teaching Internship in Public Schools (PIBID), as carried out by the Theatre Departmente at the Federal University of Rio Grande do Sul (UFRGS) at the State School General Flores da Cunha in Porto Alegre. It evaluates the contribution of the project in reactivating the theatrical activities at this school, recovering its theatrical memory and integrating pedagogical and artistic activities.

KEYWORDS: Theatre Education, Teacher Training, School, Research

\footnotetext{
${ }^{1}$ Este artigo constitui uma versão ampliada e atualizada do trabalho publicado nos anais do VI Congresso da ABRACE - Associação Brasileira de Pesquisa e Pós-Graduação em Artes Cênicas (em 2010), sob o título de Iniciação à docência em teatro: a experiência do PIBID/UFRGS.

2 Professora da Universidade Federal de Rio Grande do Sul no Departamento de Arte Dramática. Pesquisa há mais de 20 anos as relações entre Teatro e Educação, do ponto de vista tanto pedagógico quanto institucional.
} 

este texto reflete-se sobre um conjunto de ações de inserção escolar, ensino e pesquisa em teatro, processadas no decorrer do primeiro ano de uncionamento do Subprojeto da área de Teatro do Programa Institucional de Bolsa de Iniciação à Docência (PIBID), em colaboração entre o Curso de Licenci Teatro do Departamento de Arte Dramática do Instituto de Artes da Universidade Federal do Rio Grande do Sul (UFRGS) a comunidade escolar do Instituto de Educação General Flores da Cunha (IE), uma tradicional Instituição de Ensino da Rede Pública Estadual de Porto Alegre.

O texto inicia-se pela caracterização mais ampla do PIBID, através de uma explanação sobre os propósitos gerais do Projeto Institucional da UFRGS e sobre os objetivos específicos do Subprojeto da área de Teatro, tendo em vista as possibilidades e desafios que o contexto da Educação Básica Pública e a realidade da Instituição na qual o trabalho se insere significam à ação pedagógica em teatro; a seguir, são descritos e analisados diferentes tipos de atividades realizados pelos estudantes Bolsistas do PIBID Teatro da UFRGS no sentido da sua iniciação docente, que se processam na perspectiva de valorização da prática e da reflexão do teatro no meio escolar e de inserção da disciplina de teatro na Educação Básica.

Dos objetivos

O Programa Institucional de Bolsas de Iniciação à Docência (PIBID) constitui uma iniciativa pioneira de estímulo à docência em âmbito nacional, implementada pela Coordenação Geral de Desenvolvimento de Conteúdos Curriculares e de Modelos Experimentais da Diretoria de Educação Básica (DEB) Presencial, da Coordenação de Aperfeiçoamento de Pessoal (CAPES) de Nível Superior do Ministério da Educação (MEC), desde 2007, que abrange atualmente diversos estados do Brasil, integrando o Ensino Superior e a Educação Básica através da interação entre estudantes e docentes de cursos licenciatura de diferente areas do conhecimento e a realidade edu- cacional das Instituições de Ensino da Rede Pública Estadual.

Nesse sentido, o Projeto Instituciona da UFRGS $^{3}$ tem por propósito central fortalecimento das atividades de formação continuada de seus licenciandos, mediante o incentivo precoce dos futuros professore em relação à carreira docente junto à escola pública e o estímulo ao magistério na Educação Básica da Rede Estadual de Ensino.

A esse propósito alinham-se as ações específicas da equipe do Subprojeto de Teatro da UFRGS, que é composta por onze estudantes Bolsistas de Iniciação à Docência, discentes de Licenciatura em Teatro, e pelo professor Supervisor, integrante do quadro docente da escola atendida pelo Subprojeto, que atuam sob orientação da professora Coordenadora, pertencente ao quadro docente da UFRGS, responsável pela área do teatro ${ }^{4}$

A escolha do Instituto de Educação General Flores da Cunha (IE) como escola sede do Subprojeto de Teatro determinou a balho e orientou a formulação das ações do PIBID. De modo geral, a motivação por desenvolver o trabalho no IE originou-se de fatores relacionados, por um lado, à quantidade de possibilidades de ação políticopedagógica e investigativa em teatro que o envolvimento com uma instituição educacional do seu porte e da sua relevância histórica significa ao futuro professor de teatro, em especial as ações referentes ao núcleo de teatro do IE - o Teatro Infantil Permanente do Instituto de Educação (TIPIE); e, por outro lado, à perspectiva de superação de desafios impostos à ação docente em teatro nessa escola, dentre os quais de teatro no seu quadro funcional, que se reflete na carência de projetos curriculares de qualidade voltados à prática do teatro $\mathrm{e}$ à apreciação de espetáculos; as condições precárias em que se encontrava da sala de teatro da escola; e a desativação do TIPIE.

Desde a sua fundação, em 1956, pela professora Olga Reverbel (1917-2008) e suas alunas do Curso de Magistério, o TIPIE desempenhou papel de destaque no movimento de teatro estudantil do estado, tendo sido reconhecido nacionalmente entre os anos de 1960 e 1970, como um marco referencial à reflexão sobre o teatro na escola, pelo seu pioneirismo no que tange à inclusão do teatro como disciplina curricular e pela sua projeção como um espaço teatral na cidade de Porto Alegre, responsável pela difusão de espetáculos e pela promoção de eventos de natureza artística e cultural.

Entretanto, com o passar dos anos, po força do descaso histórico das políticas públicas relacionadas à educação, que parece pesar ainda mais no caso das disciplinas artísticas ${ }^{5}$, o trabalho dos docentes que sucederam Reverbel à frente da disciplina de teatro viu-se cerceado pela falta de estrutura e respaldo à ação pedagógica. Destituído de iniciativas em prol da manutenção das funções do TIPIE, esvaziado de projetos em favor da prática e da apreciação teatrais no meio escolar e, mais recentemente, privado de um professor de teatro no seu quadro docente, o IE encontra-se atualmente impedido de oferecer a disciplina de teatro no seu currículo, o que significa um retrocesso da condição precursora de escola em relação ao ensino da arte.

Nesse contexto, cabe ressaltar as condições adversas ao trabalho pedagógico, comuns a maior parte das instituições pú blicas de ensino no nosso país, ocasionadas pela carência de investimentos na ampliação (por concurso público), manutenção (mediante planos de carreira adequados e condições salariais dignas) e qualificação (através do incentivo à pesquisa e à pó

Especialmente a de teatro, devido às controvérsias que cercam a sua regula
mentaçăo como "discipinina" obrigatória no curriculo escolar, e considerando mentaçăo como "disciplina" obrigatótía no currículo escolar, e considerando ós
problemas causados no cotidiano da escola em funçao da especificidade prática dos seus conteúdos. graduação) dos quadros docentes e funcioais das escolas e na estruturação e conseração das suas dependências e instalações.

Como reflexos dessa lamentável situação têm-se aspectos que dificultam o processo de ensino e aprendizagem em qualquer área do conhecimento, tais como a superlotação das turmas e a depauperacão crescente dos espaços escolares; e, no caso das disciplinas de artes (desdobradas em artes visuais, dança, música e teatro) cuja carga-horária é restrita em relação às demais disciplinas do conhecimento (visto que as propostas curriculares costumam ser organizadas de modo a contemplar apenas uma dessas especificidades, na perspectiva de cumprir minimamente os ditames da ei), esses aspectos constituem entraves ao trabalho pedagógico, porquanto dificultam estabelecimento de vínculos entre professores e alunos e comprometem o desenvolvimento e a continuidade do processo de conhecimento; além disso, os professores de artes, que costumam lecionar em mais chituição (como alternativa complementação salarial), enfrentam problemas no estabelecimento de relações de identidade com as diferentes realidades em que atuam, bem como na sua legitimação como membro das comunidades escolare om as quais convivem. E particularmente no caso da disciplina de teatro somam-se os problemas decorrentes da carência de recursos humanos e materiais, enfrentada pelas escolas, que as impossibilita de oferecer condições específicas ${ }^{6}$ às atividades corporais e cênicas.

É no sentido da retomada e da manuenção das funções artísticas, culturais e patrimoniais do TIPIE que se configuram as ações do Subprojeto de Teatro da UFRGS, cuja equipe assume, temporariamente ${ }^{7}$, responsabilidade pelo desenvolvimento de atividades teatrais no IE, mediante experiências de ensino, aprendizagem, pesquisa 6 Ou seja: um espaço amplo, que favorecesa a movimentaçãa dos alunos, livre de
móveies o ojjettos e com piso de madeira, limpo, de modo a permitir o trabalho cor-
poral no châo, e arejado.

Os Subprojettos que integram o Edital 2009 desenvolvem-se de maio de 2010 a
maio de 2012 , ou seja, pelo período de dois anos (que pode ser ampliado, no caso de aprovaçąa em novo Editiall. 
produção e difusão do teatro, protagonizadas pela comunidade escolar do IE, sob orientação de estudantes de Licenciatura em Teatro da UFRGS.

\section{Das ações}

O momento preliminar da interação entre os estudantes Bolsistas e o PIBID ocorreu no primeiro semestre de 2010 motivado pela leitura coletiva e da dis cussão do Projeto Institucional e do Subprojeto de Teatro e de por uma primeir apreciação de documentos oficiais que regem a educação em âmbito naciona e estadual ${ }^{8}$. Tais iniciativas possibilita ram à equipe do PIBID definir formas de articulação em relação às metas propostas pelo Subprojeto de Teatro frente a objetivos específicos da área do teatro compreendidos em relação às demai áreas do conhecimento e a princípios mais amplos que norteiam os planos de estudos e as propostas pedagógicas das nossas escolas.

Como ponto de partida para o planejamento do trabalho no IE realizou-se um trabalho de sondagem, mediante o levantamento dos interesses da escola em relação ao teatro, à restauração do espaço físico do TIPIE e à identificação de tempos e espaços potenciais ao trabalho teatral. $\mathrm{O}$ trabalho envolveu também uma avaliação do ambiente e do funcionamento da escola, a fim de possibilitar a apreensão da sua realidade, o conhecimento do Projeto Político Pedagógico da escola e do Calendário Es colar, e um primeiro contato com o corpo docente da área de artes do IE.

A coleta desses dados desenvolveu-se através de visitas dos estudantes Bolsistas da Coordenadora à escola, da participação em reuniões de professores da área de artes e de conversas com a Direção e com funcionários responsáveis por diferentes setores, que possibilitaram o reconhecimento do espaço físico da escola, especialmente da

sala de teatro do TIPIE, e a avaliação das possibilidades e dos desafios da escola à prática do teatro.

Um dos primeiros fatores identificados como desafiador às ações do Subprojeto é o fato do quadro docente do IE não dispor de um professor de teatro, que in viabilizou a possibilidade de estabelecer parceria com um docente especializado na área para desempenhar a função de Supervisor dos estudantes Bolsistas em atividades na escola. Nesse sentido, conta-se com a colaboração do professor da disciplina de artes visuais (também responsável pela disciplina de música, pois possui formação nas duas áreas) na equipe do PIBID, o que configura um trabalho de mediação mais restrito ao acompanhamento dos estudantes Bolsistas em atividades artísticas de cunho interdisciplinar e a aspectos estruturais e funcionais das relações entre as propostas do PIBID e a comunidade do IE em detrimento do diálogo efetivo acerca de elementos específicos do teatro que participação que um docente da área poderia implicar.

Outra limitação eram as condições em que se encontrava o TIPIE, que prejudicavam seriamente o desenvolvimento das atividades teatrais previstas no PIBID. A situação de abandono e depredação da sala do teatro, que se agravava pela falta de manutenção e limpeza e pelo uso inapropriado e desregrado do seu espaço, foi tratada a partir de reuniões com a Direção do IE e ocasionou algumas providências imediatas $^{9}$ para contornar os problemas evidenciados, até que a recuperação do espaço do TIPIE se concluísse.

Acerca dos resultados da sondagem foram desenvolvidos registros e relatórios e elaborou-se o mapeamento (planta baixa detalhada) do espaço escolar e uma planilha com horários e contatos dos professores das disciplinas artísticas, o que facilitou

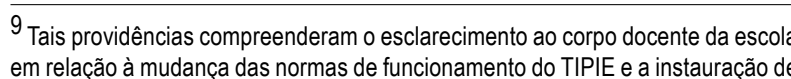

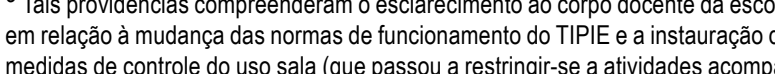

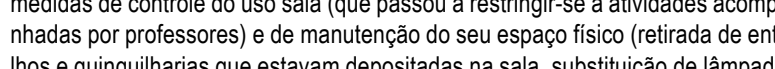
Ihose quinquilharias que estavam depositadas na sala, substituiçąa de lâmpadas
queimadas e estabelecimento de uma agenda de limpeza). a localização e o trânsito dos estudantes Bolsistas do PIBID no IE e viabilizaram sua inserção em projetos curriculares desenvolvidos na escola.

Paralelamente a esse levantamento, outra proposta buscou a inserção dos estudantes Bolsistas no cotidiano do IE mediante a participação cooperativa em experiências metodológicas atreladas a diversas disciplinas do currículo da escola (tais como: artes visuais, música, língua portuguesa e história). O planejamento dessas experiências realizou-se em conjunto com os professores das disciplinas e o trabalho envolveu observações e propostas de colaboração e intervenção pedagógica, através da abordagem de jogos tradicionais, dramáticos e teatrais, improvisações e criações cênicas a partir de elementos formais do teatro, que foram registradas, avaliadas e compartilhadas no grupo, permitindo a compreensão de aspectos do funcionamento da sala de aula e a reflexão sobre o ensino de teatro numa perspectiva global, focalizada na relação entre conhecimentos de diversas disciplinas do currículo da escola.

Outra atividade que envolveu os estudantes Bolsistas compreendeu o estudo da memória do IE e do TIPIE. O propósito dessa atividade de cunho eminentemente investigativo era favorecer a implementação de ações de revitalização da atividade teatral no contexto da escola, mediante o fortalecimento das relações de identidade entre a comunidade e o TIPIE. O trabalho envolveu uma pesquisa histórica e documental que consistiu em investigar o processo de constituição do TIPIE e a trajetória de Reverbel.

Nessa busca, os estudantes Bolsistas recorreram a documentos disponíveis no arquivo histórico da escola, com a colaboração da funcionária responsável, e ao material existente em relação à autora, $\mathrm{o}$ que incluiu suas publicações e outras obras que mencionam o seu trabalho, e realizaram resenhas e relatórios de leitura, que abrangeram: as temáticas das publicações, o contexto histórico em que elas foram concebidas e as suas relações com a carreira da utora e com o público alvo, e os vínculos das obras com o trabalho desenvolvido no TIPIE.

No decorrer das leituras constatouse que a maioria dos livros de Reverbel compreende jogos dramáticos e teatrais e ncerra reflexões sobre o ensino do teatro em diferentes níveis, abarcando desde a Educação Infantil até a formação de professores; notou-se, também, a preocupação constante da autora por ressaltar a importância do teatro como um componente curricular e os benefícios da prática teatral no desenvolvimento de crianças e jovens, bem como a busca pela construção de um método de ensino de teatro, que se desenvolve partir das suas experiências em sala de ula. Também foram lidas obras dramatúrgicas de Reverbel, concebidas durante seu rabalho no TIPIE, junto a estudantes do Magistério.

Após o trabalho de sondagem referente à estrutura da escola e às atividades artísticas desenvolvidas em diferentes disciplinas e a avaliação das intervençõe pedagógica ocorridas na sala de aula de alguns professores que se prontificaram colaborar com o PIBID, e, tendo concludo a coleta de dados para a reconstituição do memorial do TIPIE, os estudantes Bolsistas puderam dedicar-se ao trabalho de iniciação docente de cunho especificamente teatral, que se desenvolveu através de oficinas oferecidas a alunos do IE em horários alternativos (turno inverso) às suas atividades "de classe".

A proposta inaugural de oficina foi desenvolvida logo no primeiro semestre do Subprojeto e denominou-se Degustação Teatral, por se constituir uma pequena mostra das possibilidades de trabalho teatral a serem experimentadas no decorrer do Subprojeto. Nesse sentido, desenvolveram-se propostas de exploração das capacidades motoras, corporais, lúdicas, expressivas, ramáticas e representativas inerentes formalização e à comunicação cênicas, com ênfase na aprendizagem da socialização e da cooperação, fundamental ao processo de construção de conhecimento e à constituição de um grupo de jogo, e na formação 
de espectadores, primordial à reflexão sobre o fenômeno teatral.

Essa experiência docente inicial permitiu estimar os interesses dos alunos do IE em relação ao teatro e estabelecer um programa de oficinas que viesse ao encontro das necessidades da comunidade escola como um todo. O primeiro módulo do programa realizou-se no segundo semestre de 2010, através do oferecimento de oficinas nos turnos da manhã, tarde e noite, "assumidas" por duplas, ou trios, de Bolsistas, revezados nas funções de ministrantes, observadores e relatores.

O planejamento e a avaliação dos encontros das oficinas foram compartilhado em reuniões sistemáticas, o que possibilitou a combinação prévia de atividades e troca de informações e experiências entre as diferentes oficinas. No término das atividades desse primeiro módulo (em dezembro de 2010) realizou-se um evento intitulado Troca de figurinhas, no qual foram apresentados resultados cênicos obtidos em cad turma. O evento reuniu os integrantes de todas as turmas e envolveu membros da comunidade escolar e da Direção do IE contou também com a participação especial do grupo de teatro estudantil da Fundação Municipal de Artes de Montenegro (FUNDARTE-RS).

A ação docente nas oficinas do primeiro ano de atuação do PIBID no IE mobil zou a equipe em torno dos problemas concernentes à manutenção do espaço físico do TIPIE, que, embora tivessem sido ame nizados em função das medidas em relação à manutenção e ao uso mais criterioso da sala, ainda impunha sérias dificuldades a prática teatral. Frente a isso, a equipe do PIBID passou a investir esforços na instauração de uma "política de conscientização" da comunidade escolar como um todo em relação aos cuidados com o espaço do tea-

O trabalho de recuperação do TIPIE realizou-se no período de recesso das atividades letivas do IE (janeiro e fevereiro de 2011), a partir de uma tomada de orçamentos para os reparos no espaço físico da sala avaliados, desde a concepção do Subpro- jeto, como fatores imprescindíveis à retomada do núcleo teatral da escola. De modo geral, os reparos ${ }^{10}$ envolveram medidas simples e poucos recursos, mas o resultado do trabalho foi decisivo ao fortalecimento das ações do PIBID.

Assim, no segundo ano de trabalho no IE, as atividades do PIBID passaram a desenvolver-se num ambiente mais saudável e mais acolhedor à prática do teatro, o que favoreceu sobremaneira a ação pedagógica e o processo de ensino e aprendizagem nas oficinas.

Desdobradas em cinco turmas, organizadas de modo a contemplar demandas de horário de diferentes segmentos da comunidade do IE, as oficinas de teatro do segundo módulo do programa de oficinas, realizado no primeiro semestre de 2011, também são oferecidas no turno inverso das atividades de classe dos alunos interessados. Os objetivos, conteúdos procedimentos metodológicos do trabalho pedagógico desenvolvido em cada turma são estabelecidos e sistematizados levando em conta os interesses dos alunos e as necessidades que surgem no andamento do trabalho, num processo de avaliação permanente das ações dos estudantes Bolsistas na condução das propostas de ensino do teatro e do processo de aprendizagem dos sujeitos aos quais elas se dirigem.

Num rápido resumo dos objetivos traçados pelos estudantes Bolsistas em seus Planos de Ensino: na Turma A (da qual participam alunos em faixa etária entre 10 e 15 anos), evidencia-se o propósito de "estimular a criatividade e a imaginação através da proposição de jogos e improvisações" e a perspectiva de desenvolvimento de uma "dramaturgia do ator", que permita aos alunos compreenderem-se como "sujeitos do processo de criação teatral"; na oficina com a Turma $B$ (que integra jovens das séries finais do Ensino Fundamental e do Ensino Médio do IE), o objetivo pretendido é a "interação dos alunos com os elementos da ação dramática, por meio de jogos e improvisações teatrais"; na Turma $C$ (da tro aberta à comunidade escolar e apoiada qual participam crianças, jovens e adul- pela Direção do IE.

tos) tem-se por objetivos "desenvolver a construção de personagens através de improvisações" de "composições de figuras e máscaras que estimulem o imaginário dos alunos" e que favoreçam o surgimento de um corpo vivo expressivo e presente capaz de envolver-se por inteiro nas ações" e de "inserir-se no jogo e na cena teatral"; junto à Turma D (que integra alunos do Ensino Fundamental em faixas etárias diversas), o objetivo evidenciado é a ampliação da percepção, da sensibilidade e do engajamento dos participantes através do jogo, do jogo dramático e do jogo teatral; e, por fim, a oficina da Turma E, intitulada "Oficina de Voz para Professores", que cumpre uma demanda do corpo docente da escola por um trabalho de aprimoramento e sustentação vocal.

Diferentemente do sistema de oferecimento das oficinas, o trabalho dos estudantes Bolsistas do PIBID na Educação Infantil ocorre no turno regular em que as crianças frequentam a escola e realizam-se no espaço da sala de aula, e as ações pedagógicas junto aos alunos das quatro turmas contempladas são acompanhadas pelas suas respectivas professoras regentes de classe. Nessa perspectiva, o trabalho "busca incentivar a exploração de capacidades criativas dentro do faz-de-conta, através da experimentação de figuras e situações que alimentem o jogo simbólico das crianças", com vistas a desenvolver a "percepção, a expressividade corporal, a imaginação e a ludicidade"

Em conclusão às atividades das oficinas do segundo módulo está previsto um momento de compartilhamento de experiências que marcará a re-inauguração da sala de teatro do TIPIE. Nessa "segunda edição" do evento Troca de Figurinhas planeja-se contar com a apresentação de trabalhos cênicos desenvolvidos pelos estudantes Bolsistas nas disciplinas de atuação e direção em teatro que compõem currículo do Curso de Licenciatura em Teatro da UFRGS, configurando uma proposta de integração de conhecimentos em tea-

A expectativa dos integrantes do Subrojeto de Teatro do PIBID é que a coninuidade das ações implementadas no IE motive o surgimento de novos projetos m torno do ensino e da aprendizagem de conhecimentos teatrais no IE, evidencie a ecessidade de professores da área do tetro no quadro docente da escola, possiilitando o oferecimento da disciplina de teatro no seu currículo, bem como a manuenção das funções sociais, artísticas e culturais do TIPIE, e reflita-se na ampliação trabalho em teatro e no fortalecimento do teatro estudantil noutras Instituições de Ensino Público do Rio Grande do Sul e do Brasil.

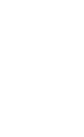

